контроля окружающей среды - 2016: тезисы междунар. науч.-практ. конф. 24-27 октября 2016. Севастополь: ИПТС, 2016. С. 119.

25. Доценко В.В. Геохимия и происхождение нефти и газа. Ростов-на-Дону: Изд-во «ЦВВР», 2007. 308 с.

26. Восьмериков А.В. Наноразмерные порошки металлов и их применение в катализе // Нанотехника. 2008. № 1. C. 27-32.

27. ГОСТ 28168-89. Межгосударственный стандарт. Почвы. Отбор проб. Издание официальное. Введ. 01.04.1990. М.: Стандарт информ, 2008. 7 с.

28. Методика выполнения измерений массовой доли кислоторастворимых форм тяжелых металлов и токсичных элементов (Cd, Pb, Cu, Zn, Bi, Tl, $\mathrm{Ag}, \mathrm{Fe}$, $\mathrm{Se}, \mathrm{Co}, \mathrm{Ni}, \mathrm{As}, \mathrm{Sb}, \mathrm{Hg}, \mathrm{Mn}$ ) в почвах, грунтах, донных отложениях, осадках сточных вод методом инверси- онной вольтамперометрии. ФР.1.34.2005.01734. М.: ЗАО «НПКВ Аквилон», 2005. 42 с.

29. ГН 2.1.7.2511-09. Ориентировочно-допустимые концентрации (ОДК) химических веществ в почве: Гигиенические нормативы. М.: Федеральный центр гигиены и эпидемиологии Роспотребнадзора, 2009. $11 \mathrm{c}$

30. Виноградов А.П. Геохимия редких и рассеянных химических элементов в почвах. М.: АН СССР, $1957.238 \mathrm{c}$.

31. Ильбулова Г.Р., Ильбулова Г.Р., Биктимерова Г.Я., Семенова И.Н., Семенова И.Н. Аккумуляция меди растениями Bromopsis inermis (Leys.) в условиях техногенного загрязнения // Международный журнал прикладных и фундаментальных исследований. 2015. № 12. Ч. 8. С. 1471-1475.

\title{
FEATURES OF COPPER ACCUMULATION IN THE SOILS OF DIFFERENT FUNCTIONAL AREAS OF NOVOKUYBYSHEVSK
}

\section{(C) 2019}

Startsev Alexander Igorevich, postgraduate student of Ecology, Botany and Nature Protection Department Samara National Research University (Samara, Russian Federation)

Abstract. The vegetation of the Samara Region is characterized by a relatively high content of copper. This biogeochemical feature is typical for natural and technogenic transformed ecosystems of the region. Copper is included in the group of elements of the $2^{\text {nd }}$ hazard class. At certain concentrations it is necessary for the normal functioning of all organisms, but with increasing concentrations in the environment or in food it shows toxicity. The technogenic sources of copper include metalworking and machine-building enterprises, fertilizers, road and rail transport, wastewater, products of incomplete fuel combustion and refining characteristic of the Samara Region. The peculiarities of copper accumulation and distribution in soils of urban areas of the region are insufficiently studied. Previously, such studies were carried out only in certain areas of Samara. The paper analyzes in detail the level of technogenic copper pollution of the soil cover in Novokuybyshevsk. Ecological and geochemical studies in Novokuybyshevsk were carried out for 3 years (2016-2018) on 7 stationary test plots in its different functional areas and on 1 background test plot. The objects of research were soil samples taken from the upper humus horizon (layer $0-10 \mathrm{~cm}$ ). The quantitative content of copper in soil samples was determined by the method of inversion voltammetry. A comparative analysis revealed territories of Novokuybyshevsk with relatively high, medium and low levels of copper in the soil. The first group included the Park «Dubki» in its elevated part, the old residential area on Kirov Street, the roadside area at the intersection of Pobeda Avenue and Dzerzhinsky Street (93,3-90,7 mg/kg). The second group with an average copper content $(71,0-73,3 \mathrm{mg} / \mathrm{kg})$ included the square «Elochki» and a new residential area on Ostrovsky Street. The third group with a relatively low copper content $(38,3-54,7 \mathrm{mg} / \mathrm{kg})$ included three sample areas: the lowland part of the Park «Dubki», the industrial zone and the background area. The concentration of copper in the soils of all studied functional zones in Novokuybyshevsk has not reached the level of approximate permissible concentration (APC), but more than the clark of the world soils and the background indicators. The downward trend in the concentration of copper in the soils of most of the studied functional zones of Novokuybyshevsk in 2018 compared with 2016 and 2017 at the relatively low level of copper content in soils of the industrial area of the city allows to exclude oil refineries from the list of its major anthropogenic sources.

Keywords: Novokuybyshevsk; Samara Region; urban areas; functional zones; heavy metals; copper; petrochemical manufacturing; industrial pollution; soils; migration of elements; approximate permissible concentration (APC); background indicators; ecological-geochemical monitoring; sources of heavy metals.

УДК 581.9

DOI 10.24411/2309-4370-2019-12113

Статья поступила в редакцию 09.02.2019

\section{СОВРЕМЕННОЕ ЭКОЛОГО-БИОЛОГИЧЕСКОЕ СОСТОЯНИЕ АДВЕНТИВНОЙ ФЛОРЫ БАССЕЙНА РЕКИ СВИЯГИ}

(C) 2019

Фролов Даниил Анатольевич, кандидат биологических наук, доцент кафедры биологии и химии, декан естественно-географического факультета Ульяновский государственный педагогический университет имени И.Н. Ульянова (2. Ульяновск, Российская Федерация)

Аннотация. В статье приводятся сведения об адвентивной фракции флора бассейна реки Свияги, правого притока Волги, административно протекающего по территории Ульяновской области и Республики Татарстан. В настоящее время по результатам многолетних флористических исследований к адвентивной флоре бассейна реки Свияги отнесено 346 видов сосудистых растений, входящих в состав 217 родов и 65 семейств. 
Приводятся анализ распределения адвентивных видов флоры по степени натурализации, времени и способу заноса, который показывает, что большинство адвентивных видов растений флоры попадали на территорию бассейна с конца 19 и до середины 20 веков из-за роста процессов экономической интеграции с последующим расширением коридоров транспортных сетей, с последующим закреплением, по нарушенным антропогенным местообитаниям. Из которых наиболее экологически пластичные смогли интегрироваться в естественные природные сообщества. Помимо распределения видов-адвентиков по времени, способу заноса и степени натурализации важным показателем является адаптация данных растений к локальным условиям бассейна реки Свияги в природных экосистемах, что отражено в их распределение по ценоморфам на исследуемой территории. В составе адвентивной флоры было выделено 9 эколого-ценотических групп, свидетельствующие с одной стороны, какие сообщества наиболее благоприятны для натурализации в соответствии с жизненной стратегией, а с другой - служит показателем их нарушенности.

Ключевые слова: бассейн реки; река Свияга; растительность; видовое разнообразие; биоразнообразие; фитоценоз; стратегии выживания биологических видов; адвентивная флора; археофиты; кенофиты; ксенофиты; эпекофиты; агриоэпекофиты; агриофиты; колонофиты; эфемерофиты; антропоценоз; ценоморфы.

\section{Введение}

Бассейн реки Свияги локализован в лесостепной зоне лесостепной провинции центральной части Приволжской возвышенности и относится к бассейну реки Волги [1].

На территории объекта исследования, как и на большей части Средневолжского бассейна, природная флора и растительность претерпела интенсивную синантропизацию и как следствие стала антропогенно-трансформированной. Ключевое значение при этом имело развитие сельского хозяйства, сведение лесов и расширение сети транспортных коммуникаций [2-5].

\section{Методика исследования}

Современная адвентивная фракция флоры бассейна реки Свияги включает 346 видов сосудистых растений, относящихся к 217 родам и 65 семействам.

Доля адвентивных видов в представленной флоре составляет около $1 / 4$ от всей флоры бассейна реки Свияги $-25,7 \%$, являясь таким образом показателем активно происходящих процессов синантропизации естественного растительного покрова территории [6-8].

Для оценки степени антропогенной трансформации флоры Свияжского бассейна была проанализирована её адвентивная фракция, выделенная на основании многолетних флористических исследований на рассматриваемой территории, а также ботанических сводок по Ульяновской области и Республике Татарстан $[9 ; 10]$.

\section{Результаты исследования и их обсуждение}

Современное адвентивное ядро флоры бассейна p. Свияги сформировано в той или иной степени способными к натурализации видами, образующими её устойчивый компонент. Основу стабильного компонента составляют эпекофить - Ceratocephala falcata (L.) Pers, Consolida regalis S.F. Gray, Glaucium corniculatum (L.) J. Rudolph, Cannabis ruderalis Janisch и др. Всего 139 видов или 40,2\% всей адвентивной флоры. Aгриоэпекофить - Saponaria officinalis L., Bunias orientalis L., Salix fragilis L., Parthenocissus inserta (A. Kern.) Fritsch, всего 31 вид $(9,2 \%)$ и агриофumbl (14; 4,2\%) - Swida alba (Cornus alba L.), Echinocystis lobata (Michx.) Torr. et Cray., Elaeagnus angustifolia L., Phragmites altissimus (Benth.) Nabille и др. в сумме представленные 183 видами, преимущественно ксенофитами (такими как Acorus calamus L., Eragrostis minor Host., Xanthium albinum (Widd.) H. Scholz и др.), составляющими 53,7\% всей адвентивной фракции.
Неустойчивый компонент адвентивной фракции флоры формируется за счёт эфемерофитов (91 вид; $27 \%$ ) и колонофитов (66 видов; 19,4\%), в сумме составляющих 157 видов (47\% всей адвентивной флоры), представлен такими видами как Eschscholtzia californica Cham., Amaranthus caudatus L., Fagopyrum esculentum Moench, Abutilon theophrasti Medik., Vitis vinifera L. и многими другими.

Ксено-эргазиофить - виды с промежуточным типом заноса, составляют небольшую часть изученной флоры адвентиков (33 вида или 9,5\%).

Натурализация видов в Свияжском бассейне, подтверждает мнение ряда учёных [11-13], что каждый более глубокий этап вхождения в естественные природные сообщества, представляет все большую трудность, и поэтому на каждом последующем этапе, число натурализовавшихся видов-адвентиков сокращается.

Исследование адвентивного ядра флоры по изучению способов заноса показало незначительное преобладание в адвентивной флоре Свияжского бассейна видов - ксенофитов, попавших на исследуемые территории случайно (Lappula patula (Lehm.) Menyharth., Datura stramonium L., Hyoscyamus niger L., Galeopsis bifida Boenn., Stachys annua (L.) L., Coniza canadensis (L.) Cronq. и др.).

На их долю приходится 48,0\% от общего видового состава адвентивной фракции. Виды, ранее целенаправленно занесенные человеком, составляют $42,3 \%$ адвентивной фракции. Постепенно в ходе акклиматизации, у части из них наблюдается дичание с последующим вхождением в состав естественных фитоценозов.

Проведенный анализ адвентивной фракции флоры бассейна Свияги по времени заноса показал, что большая часть видов-адвентиков попала на изучаемую территорию с конца XIX до середины XX века (кенофиты составляют 70,0\% от всех адвентивных видов).

Apxeофить - в сумме составляют почти треть видового разнообразия адвентивной фракции флоры, представлены 103 видами, среди которых наиболее часто встречаемые Malus domestica Borkh., Pyrus communis L., Pisum arvense L., Erodium cicutarium (L.) L'Her, Cynoglossum officinale L.

Доминирование кенофитов связано с расширением сети транспортных путей, активными процессами роста городских территорий, усилением экономических связей, и, как следствие, прямое увеличение площади антропоценозов, становящихся благоприятными плацдармами для внедрения адвентивных видов в биоту. 
Сходные процессы отмечаются исследователями не только в районах Среднего Поволжья, но и Центральной России [14; 15$]$.

Таким образом, большая часть видов адвентивной фракции флоры проникла на территорию Свияжского бассейна в течение XX века, благодаря расширению коридоров транспортных сетей, увеличению товарооборота между регионами, прокладкой разнообразных транспортных коммуникаций, активной урбанизацией и как следствие - резкая синантропизация растительного покрова. Адвентивные виды при этом занимали преимущественно нарушенные местообитания, но, несмотря на это, в настоящее время являются постоянным элементом флоры.

Одним из ключевых показателей стратегии адаптации видов-адвентиков к локальным условиям, является их участие в сложении природных экосистем, отраженное в распределении растений по группам ценоморф различных местообитаниях на территории исследования.

Если в аборигенной флоре Свияжского бассейна выделено 11 эколого-ценотических групп с учетом приуроченности видов растений к определённым условиям произрастания, то адвентивные виды, в той или иной степени присутствуют только в 9 из них, что показывает с одной стороны - какие сообщества наиболее благоприятны для натурализации, а с другой - служат показателем их нарушенности и степени антропогенной трансформации (табл. 1).

Ряд исследователей отмечают, что натурализация адвентивных видов легче происходит в тех фитоценозах и экосистемах, где снижена конкуренция и вид, как следствие может легко занять пустующие экологические ниши [16-20].

Обзор эколого-фитоценотического спектра закономерно показал - большая часть видов адвентивной флоры бассейна реки Свияги сосредоточено в сорных рудеральных и сегетальных растительных сообществах и группировках $(82,1 \%)$, что отражает их постоянную возобновляемую нарушенность в результате хозяйственной деятельности человека и изза этого резко сниженную конкуренцию, позволяю- щую сорным видам, среди которых преобладают эксплеренты, массово размножаться и быстро занимать подобные антропогенные экотопы. Это прежде всего адвентивные виды-рудералы из родов марь (Chenopodium), лебеда (Atriplex), верблюдка (Corispermum), спорыш (Polygonum), полынь (Artemisia), костер (Bromus) и др.

Вторыми по освоенности адвентивными видами являются природные степные экосистемы $(5,6 \%)$, где наибольшее количество заносных видов отмечается в типичных степных сообществах $(57,1 \%)$, что закономерно отражает активную эксплуатацию сохранившихся нераспаханных степей как пастбища. При этом при экстенсивном выпасе скота в степных сообществах постоянно создаются микронарушения, по которым и происходит внедрение адвентивных видов-ксерофитов, таких как бурачок туркестанский (Alyssum turkestanicum Regel et Schmalh.), рогоглавник серповидный (Ceratocephala falcata (L.) Pers.), солянка холмовая (Salsola collina Pall.), мортук восточный (Eremopyrum orientale (L.) Jaub. et Spach.), a по нарушенным песчаным степям - верблюдки Маршалла (Corispermum marschallii Stev.) и верблюдки восточной (Corispermum orientale Lam.).

Следующие по значимости экосистемы, которые легко осваивают адвентивные виды, - прибрежноводные сообщества и группировки $(3,5 \%)$, среди которых ведущую роль играют пионерные сообщества песчаных отмелей и кос берегов рек, ежегодно обновляющиеся после весеннего паводка. Они в силу природных особенностей отличаются пониженной конкуренцией, что позволяет заносным видам, таким как дурнишник обыкновенный (Xanthium strumarium L.), дурнишник беловатый (Xanthium albinum (Widd.) H. Scholz), мелколепестничек канадский (Conyza canadensis (L.) Cronq.), ослинник двулетний (Oenothera biennis L.) и ослинник красностебельный (Oenothera rubricaulis Klebahn.) образовывать монодоминантные маловидовые пионерные сообщества на легких прибрежных песчаных субстратах у реки Свияги и широко распространяться по подобным местообитаниям по её притокам.

Таблица 1 - Эколого-фитоценотический состав аборигенной и адвентивной фракции флоры бассейна реки Свияги

\begin{tabular}{|l|c|c|c|}
\hline \multirow{2}{*}{ Эколого- } & \multicolumn{3}{|c|}{ Флора бассейна реки Свияги } \\
\cline { 2 - 4 } & Аборигенная фракция & Адвентивная фракция & Общая флора \\
\cline { 2 - 4 } & \multicolumn{2}{|c|}{ абсолютное число видов / доля от общего числа видов, \% } \\
\hline Лесная & $188 / 19,0$ & $10 / 2,7$ & $197 / 14,8$ \\
\hline Степная & $146 / 14,9$ & $19 / 5,6$ & $165 / 12,5$ \\
\hline - собственно степная & $75 / 7,7$ & $11 / 3,2$ & $86 / 6,6$ \\
\hline - кальцефильно-степная & $31 / 3,1$ & $2 / 0,6$ & $33 / 2,5$ \\
\hline - псаммофильно-степная & $24 / 2,4$ & $5 / 1,5$ & $29 / 2,2$ \\
\hline - петрофильно-степная & $13 / 1,3$ & - & $13 / 1,3$ \\
\hline - галофильно-степная & $3 / 0,3$ & $1 / 0,3$ & $4 / 0,3$ \\
\hline Луговая & $126 / 12,9$ & $7 / 1,8$ & $131 / 9,9$ \\
\hline Прибрежно-водная & $115 / 11,9$ & $12 / 3,5$ & $127 / 9,7$ \\
\hline Лесостепная & $96 / 9,7$ & $5 / 1,0$ & $99 / 7,5$ \\
\hline Полянно-опушечная & $98 / 9,8$ & $8 / 2,6$ & $107 / 8,1$ \\
\hline Сорная & $63 / 6,4$ & $280 / 82,1$ & $343 / 25,8$ \\
\hline - сегетальная & $14 / 1,4$ & $40 / 11,7$ & $54 / 4,1$ \\
\hline - рудеральная & $49 / 5,0$ & $240 / 70,4$ & $289 / 21,7$ \\
\hline Лугово-степная & $55 / 5,6$ & $4 / 1,0$ & $58 / 4,4$ \\
\hline Болотная & $43 / 4,5$ & - & $43 / 3,3$ \\
\hline Водная & $33 / 3,3$ & $1 / 0,3$ & $34 / 2,6$ \\
\hline Лугово-болотная & $24 / 2,4$ & - & $24 / 1,8$ \\
\hline
\end{tabular}




\section{Bывод}

Реализация адаптивных жизненных стратегий адвентивными видами позволяет им успешно конкурировать с местными видами и расселяться во вторичных ареалах. В бассейне реки Свияги, в большинстве случаев, такое расселение происходит по природным нарушенным степным экосистемам и пионерным прибрежно-водным сообществам, в которых адвентивные виды легко занимают определенную нишу и быстро встраиваются в трофические цепи питания.

\section{Список литературы:}

1. Растительность Европейской части СССР / ред. С.А. Грибова, Т.И. Исаченко, Е.М. Лавренко. Л.: Наука, 1980. 429 с.

2. Бурда Р.И. Критерии адаптации региональной флоры к антропогенному влиянию // Изучение биологического разнообразия методами сравнительной флористики: мат-лы IV рабочего совещания по сравнительной флористике. СПб.: СПб. гос. ун-т (НИИХ), 1998. С. $260-272$.

3. Малышева В.Г. Пути и способы формирования адвентивной флоры Калининской области // Флора и растительность южной тайги: межвуз. сб. Калинин: Изд. КГУ, 1988. С. 109-112.

4. Туганаев В.В., Пузырев А.Н. Гемерофиты Вятско-Камского междуречья. Свердловск: Изд-во Урал. ун-та, 1988. $128 \mathrm{c.}$

5. Юрцев Б.А. Флора как природная система // Бюллетень МОИП. Отд. биол. 1982. Т. 87, вып. 4. C. 3-32.

6. Фролов Д.А. Итоги изучения урбанофлоры бассейна реки Свияги города Ульяновска // Современные проблемы морфологии и репродуктивной биологии семенных растений: мат-лы междунар. конф., посв. памяти Р.Е. Левиной (Ульяновск, 14-16 октября 2008 г.): сб. научных тр. Ульяновск: УлГПУ, 2008. C. $320-327$.

7. Фролов Д.А. Степная флора антропогеннотрансформированных ландшафтов Цильнинского района в бассейне реки Свияги // Природа Симбирского Поволжья: сб. науч. тр. Ульяновск: Издательство «Корпорация технологий продвижения», 2006. Вып. 7. С. 88-94.

8. Фролов Д.А., Масленников А.В. Конспект флоры бассейна реки Свияги. Ульяновск: Изд-во УлГПУ, 2010. 144 c.

\section{THE CURRENT ECOLOGICAL AND BIOLOGICAL STATE OF THE ADVENTIVE FLORA OF THE SVIYAGA RIVER BASIN}

(C) 2019

Frolov Daniil Anatolievich, candidate of biological sciences,

associate professor of Biology and Chemistry Department, dean of Faculty of Natural Sciences and Geography Ulyanovsk State Pedagogical University (Ulyanovsk, Russian Federation)

Abstract. The paper provides information about the adventive fraction of the flora of the Sviyaga River basin, the right-hand tributary of the Volga, which flows administratively through the territory of two constituent entities of the Russian Federation - the Ulyanovsk Region and the Republic of Tatarstan. Currently, according to the results of perennial floristic studies, 341 species of vascular plants belonging to 216 genera and 64 families are assigned to the adventive fraction of flora. The distribution of adventive flora species by time, method of introduction and degree of naturalization is analyzed, which showed that the majority of the adventive fraction of flora penetrated into the studied area over the past 100 years due to the expansion of the transport network, intensive trade and active urbanization, while «aliens» occupied mostly disturbed habitats, often becoming elements integrated into natural communities of nature. In addition to the distribution of adventist species over time, the method of introduction and the degree of naturalization, an important indicator is the adaptation of these plants to the local conditions of the Sviyaga River 
Basin in natural ecosystems, which is reflected in their distribution by cenomorphs in the study area. As part of the adventive flora, 9 ecological-cenotic groups were identified, indicating, on the one hand, which communities are most favorable for naturalization in accordance with the life strategy, and on the other, it indicates their disturbance.

Keywords: river basin; Sviyaga River; vegetation; species diversity; biodiversity; phytocoenosis; species survival strategies; adventive flora arheophytes; kenophytes; xerophytes; epekophytes; agrioepekophytes; agriophytes; kolonophytes; ephemerophytes; anthropocoenosis; coenomorphs.

\title{
МЕТОДОЛОГИЧЕСКИЙ ПОДХОД К ОЦЕНКЕ ЭКОЛОГИЧЕСКОГО СОСТОЯНИЯ ВОДНЫХ ОБЪЕКТОВ С ИСПОЛЬЗОВАНИЕМ КОМПЛЕКСНОГО ИНДЕКСА КАЧЕСТВА ВОДЫ НА ПРИМЕРЕ СРЕДНЕГО ПРИОБЬЯ
}

(C) 2019

Шорникова Елена Александровна, кандидат биологических наук, доцент кафедры экологии и биофизики Сургутский государственный университет

(2. Сургут, Ханты-Мансийский автономный округ - Югра, Российская Федераиия)

\begin{abstract}
Аннотация. В статье представлен методологический подход и опыт использования комплексного индекса качества воды $I_{w q}$ для оценки экологического состояния поверхностных водных объектов по результатам мониторинга водотоков бассейна Средней Оби в период 2002-2018 гг. Данный индекс позволяет использовать в качестве первичной информации результаты гидрохимических наблюдений, показатели структуры микробного сообщества и другие доступные данные, полученные для конкретных контрольных створов на различных водных объектах в пределах водосборного бассейна. В качестве критерия оценки при расчете данного индекса используется степень отклонения каждого контролируемого показателя от среднего значения данного показателя, полученного для всей исследованной акватории в пределах водосборного бассейна. По рассчитанным значениям индекса качества воды $I_{w q}$ водным объектам присваивается класс и категория качества вод. Такой методологический подход позволяет осуществлять сравнительную оценку экологического состояния водных объектов и их участков в пределах водосборного бассейна, дает возможность картографировать полученную информацию, анализировать возможные причины ухудшения состояния водных экосистем, принимать управленческие решения по их восстановлению. В данной работе представлены результаты использования комплексного индекса качества воды для рек бассейна Средней Оби по гидрохимическим показателям и количественным параметрам структуры микробного сообщества.

Ключевые слова: водные объекты гидросферы; водные экосистемы; Средняя Обь; мониторинг водных экосистем; гидрохимические показатели; антропогенная нагрузка; оценка качества воды; структура микробного сообщества; комплексные индексы; индекс качества воды; экологическое состояние водных объектов.
\end{abstract}

\section{Введение}

Современная система мониторинга водных объектов гидросферы в РФ основана на отборе проб воды и донных отложений, проведении перечня химических анализов по определенной программе исследований, сопоставлении полученных результатов с нормативами предельно-допустимых концентраций (ПДК) для водоемов определенной категории водопользования [1-2]. В некоторых случаях программой мониторинга предусматривается процедура биотестирования. Заключение о качестве воды и экологическом состоянии водного объекта осуществляется по количеству показателей, превышающих нормативы ПДК, кратности превышения ПДК, результатам биотестирования. При этом субъекты мониторинга сталкиваются с необходимостью интерпретировать большие объемы цифровых данных, которые требуется обработать, систематизировать, представить определенным образом, что составляет довольно трудоемкий и длительный процесс [3, с. 3]. Следовательно, выявление источников антропогенного воздействия, и далее принятие управленческих решений по восстановлению водной экосистемы может быть отложено на неопределенный срок, который может растянуться на многие месяцы. Одним из вариантов решения таких трудностей является расчет комплексных индексов, позволяющих оценить состояние водного объекта по совокупности показателей. В процессе обработки материалов, полученных при мониторинге водных объектов бассейна Средней Оби, нами было апробировано несколько комплексных индексов оценки качества вод, некоторые результаты были ранее опубликованы [4-8].

Целью настоящего исследования являлось апробирование различных интегральных методов оценки качества воды водных объектов гидросферы и разработка методологического подхода к оценке состояния водных объектов с учетом региональных геохимических характеристик.

Автор выражает благодарность В.Н. Тюрину за помошь в составлении карты-схемы расположения контрольных створов на водотоках Среднего Приобья, О.Н. Корниловой, В.Н. Ранченковой, студентам кафедры экологии СурГУ за помощь в выполнении полевых и экспериментальных работ.

\section{объект и методы исследования}

Данное исследование было выполнено на реках широтного отрезка Средней Оби. Широтный отрезок Средней Оби протяженностью более 300 км располагается в центральной части Западной Сибири в границах Нижневартовского, Нефтеюганского и Сургутского административных районов Ханты-Мансийского автономного округа - Югры. Данный участок Среднего Приобья характеризуется высокой водо- 